\title{
A rejection of doctors as moral guides
}

\author{
Dame Elizabeth Ackroyd Chairman, Patients Association
}

\section{Editor's note}

Rejecting the claim that patients have a moral obligation to themselves to preserve their own health and thus a moral obligation to follow their doctors' medical advice, the Chairman of the Patients Association suggests that a more equal partnership between doctor and patient, based on better communication, plus reasonable concern for their own health on the part of all are the objectives justifiably pursued in the common interest.

Drs Sider and Clements argue that one has a moral obligation to oneself to keep in good health: and by implication that since in general doctors know best how one can keep in good health one has a moral obligation to follow doctors' advice.

While I can accept on utilitarian grounds that overall welfare is best served if one does try to keep in reasonable health, I find it difficult to clothe this claim in the portentous terms of moral obligation which $\mathrm{Dr}$ Sider and Dr Clements use.

Indeed I view with some reserve the self-regarding emphasis of their thesis. I agree that people who disregard treatment which would improve their health and enable them to carry out their jobs better (as in the case they quote of the hypertensive cleric) could be regarded as selfish, but on the other hand someone who is preoccupied with maintaining good health - stuffing himself with bran, jogging, ostentatiously and (probably) eschewing foods which his companions may be enjoying - could equally be regarded as selfish in his relations with other people since his activities may make these people feel uncomfortable and selfconscious as they pursue their mildly self-indulgent way of life.

Of course some of us are more than mildly selfindulgent and if this leads to ill-health can legitimately be condemned in this country as imposing a reprehensible burden on the National Health Service and therefore on the British tax-payer.
Having nailed my colours to the utilitarian mast, $\overline{\mathrm{B}}$ readily agree that in practical terms Drs Sider and Clements and I can share common ground in some $\vec{O}$ respects. In the first place, there are a number of ways $\omega$ in which people's reckless disregard for their health $\vec{A}$ alcohol excess is an outstanding example at present -0 can be very costly to the community, both in financiaP terms and in personal terms of family relationships $\vec{C}$ Less obviously in social terms, the lack of self $\frac{\mathbb{D}}{0}$ discipline which is shown in our consumption of sugard and animal fats and to which the relatively high incidence of heart disease in the United Kingdom is attributed, has repercussions on the cost of the health $\overrightarrow{0}$ service. From this point of view I believe that $e_{+}^{\infty}$ Department of Health should be more active promoting health education here.

These comments do not mean incidentally, that accept the contention of $R M$ Veatch as described by the authors that 'when people voluntarily risk theiro health they are morally required to pay the extra costs themselves'. There would be too many imponderablesi $\vec{B}$ in any individual case for it to be possible to make a fair judgement on where the cost should fall.

I also welcome, as a useful contribution to a patient's health care, the authors' implication of the benefits of a closer relationship between doctor and patient. But emphatically reject their assertion in their conclusion that doctors 'are moral guides in the realm of health' and their statement that in disregarding their doctors advice patients 'risk violating fundamental ethica $\widehat{5}$ obligations and invite justifiable disapproval'? Moreover they say nothing about the doctor's ethicab obligation to his or her patient. The Patients Association believes that too often this obligation $N$ based on the expertise and experience of the doctor vis $a$ vis his patient, is not adequately observed.

We seek to promote a more equal partnership ${ }^{\omega}$ between doctor and patient, based on better communication, not the relationship of guru ande disciple which Drs Sider and Clements seem in essences? to favour.

\section{Key words}

Doctor-patient relationship; obligation; health. 